\title{
Genetics Education
}

\section{The Normative and the Empirical}

\author{
Kostas Kampourakis ${ }^{1}$
}

Published online: 23 November 2017

(C) Springer Science+Business Media B.V., part of Springer Nature 2017

As is well known to the readers of this journal, history of science can inform the teaching of science in various ways. Whereas the historical development of science does not exactly parallel individual conceptual development, there are important lessons to be learned for science teaching by looking at the history of science. For instance, one can look at the obstacles that past scientists had to overcome and get insights about similar obstacles that students face. Furthermore, the historical development and evolution of concepts, such as the gene, is important to look at because the concepts that we use and teach about today are the outcomes of history and so it is important to know where it all started and how we got where we are today. Philosophy of science has an important role to play here as well, for instance in clarifying concepts: what genes are and are not, and what genes do and do not do. And if you think that I have forgotten about sociology of science, I have not: the "rediscovery" and reification of Mendel has been an exemplar case study for sociologists of science. In this sense, history, philosophy, and sociology of science can provide educators with important insights and ideas about how to structure teaching about genetics. This is the normative dimension, which is important.

However, no matter what history, philosophy, and sociology of science suggest, one should also keep in mind the empirical dimension: what actually works and does not work with students and teachers in classrooms. For instance, to take the topic of an article in this issue as an example, there might be several arguments about whether we should keep teaching Mendelian genetics in the beginning of genetics courses and before molecular genetics, or whether this "usual" genetics curriculum should be reversed. There have been arguments for both views. On the one hand, some people have argued that despite the problems and the oversimplifications of Mendelian genetics, it is a model easy to grasp with a great heuristic value, both in the historical development of the science of genetics and for students' own understanding of the topic. On the other hand, some people have argued that we have had enough with this model that is not the representative of most genetics-related phenomena, at

Kostas Kampourakis

Kostas.Kampourakis@unige.ch

1 Section of Biology and IUFE, University of Geneva, Geneva, Switzerland 
least as we currently understand them, and that we should give students an idea of the respective phenomena at the molecular level and of the underlying complexity, before turning to the classic Mendelian view.

There are advantages and disadvantages in both views, and one might have good arguments for one or the other view. However, I argue that any thoughtful decision should also consider empirical findings from classrooms: what works best for students, and what improves their understanding. Whereas the available research does not (yet) provide a definitive answer to this question, my point is that any curricular decision should take into account both the normative and the empirical dimension. This is why this issue of Science \& Education brings together articles on genetics education that overall have a distinctively empirical character, perhaps one that we do not usually encounter in this journal. Whereas readers of this journal appreciate the insights from HPS scholarship, we should also look more and more closely at the empirical findings of the application of HPS-related teaching. Genetics is one such case, and there are of course a lot more in this journal. I hope that the research and the conclusions presented in the articles of this issue would be of interest not only to biology educators, but also to educators in other fields.

\section{Compliance with ethical standards}

Conflict of interests The author declares no conflict of interest. 